\title{
Interactive comment on "Coupling a gas chromatograph simultaneously to a flame ionization detector and chemical ionization mass spectrometer for isomer-resolved measurements of particle-phase organic compounds" by Chenyang Bi et al.
}

Chenyang Bi et al.

chenyangbi@vt.edu

Received and published: 5 November 2020

The authors would like to thank all the reviewers for reviewing our manuscript and for providing incisive and constructive feedback to help us improve the quality of this paper and to address some issues that required further clarification and discussion. We have made revisions to our original manuscript accordingly. Because the two reviewers have raised similar scientific concerns and discussion points, we have responded 
to all reviewers in a combined document. Responses to this Reviewer (Anonymous Reviewer \#1) are on pages 1-6

Please also note the supplement to this comment:

https://amt.copernicus.org/preprints/amt-2020-264/amt-2020-264-AC1-

supplement.pdf

Interactive

comment

Interactive comment on Atmos. Meas. Tech. Discuss., doi:10.5194/amt-2020-264, 2020. 